\title{
Magnesium Bromide Promoted Barbier-Type Intramolecular Cyclization of Halo-Substituted Acetals, Ketals, and Orthoesters
}

\author{
Jui-Wen Huang, Chiar-Dy Chen, Man-kit Leung* \\ Department of Chemistry, National Taiwan University, Taipei, Taiwan, R. O. C.
}

Received 25 June 1999; accepted 22 September 1999

\begin{abstract}
Although acetals, ketals and orthoesters are commonly used as protective groups against organometallic reagents, Grignard reagents derived from halo-acetals, ketals, or orthoesters cyclize intramolecularly under $\mathrm{MgBr}_{2}$ promoted conditions, giving rise to the corresponding cycloalkanol and cycloalkanone derivatives. Our results also suggest a Lewis acid catalyzed push-pull mechanism operating for the cyclization. (c) 1999 Elsevier Science Ltd. All rights reserved.
\end{abstract}

Because of their high stability towards Grignard reagents, protection of carbonyl compounds as acetals or ketals becomes a very common and valuable tactic during synthesis. ${ }^{1}$ However, on treatment of $\omega$-haloacetals with magnesium, formation of unexpected intramolecular cyclization products is occasionally observed.2.3e This observation prompted us to investigate the details of this one-step cyclization. A survey of the chemical literature, as well as our preliminary experimental results, revealed that the relevant Grignard reagents could be effectively prepared in $\mathrm{THF}^{3}{ }^{3}$ In diethyl ether, however, the reaction is in general difficult to initiate. Although addition of 1,2-dibromoethane as a promoter does trigger the reaction, formation of the intramolecular cyclization product is inevitable. More interesting is the fact that the yield of the cyclization product $1 \mathrm{a}$ from 1 (Table 1) increased with increasing amounts of $\mathrm{BrCH}_{2} \mathrm{CH}_{2} \mathrm{Br}$ used. Maximum yield was obtained when over 4 equivalents of $\mathrm{BrCH}_{2} \mathrm{CH}_{2} \mathrm{Br}$ were employed. In addition, polymerization does not occur under these conditions. Since $\mathrm{MgBr}_{2}$ is generated from $\mathrm{BrCH}_{2} \mathrm{CH}_{2} \mathrm{Br}$ during the course of reaction, ${ }^{4}$ the success of the cyclization is likely attributable to a Lewis-acid assisted mechanism. 5

Under our conditions, as the results in Table 1 show, the three and five membered ring precursors 1.5 deliver cyclized products in higher yields. In addition, the $\omega$-haloalkyl-1,3-dioxolanes 3 and 8 cyclize more effectively than the corresponding 1,3-dioxane precursors 2 and 7 . The difference in cyclization behavior of these systems clearly outlines the reaction mechanism. The order of $3-5>4$ for the ring-closures is in good agreement with the general trend for kinetically-controlled intramolecular cyclization, ${ }^{6}$ indicating that the ringclosure process is the rate-determining step. On the other hand, our experimental results also suggested that the acetal ring opening process should be involved in the transition state. Strain released from ring-opening of the 
Table 1: Magnesium Bromide Promoted Barbier-Type Intramolecular Cyclization of Halo-Substituted Acetals, Ketals, and Orthoesters

(y)

five-membered 1,3-dioxolane could partially compensate for the activation energy and therefore be beneficial for the cyclization. On the contrary, the less strained 1,3-dioxanes are relatively stable and therefore sluggish towards the acetal ring-opening process. All these observations are indeed consistent with a Lewis acid catalyzed push-pull mechanism.

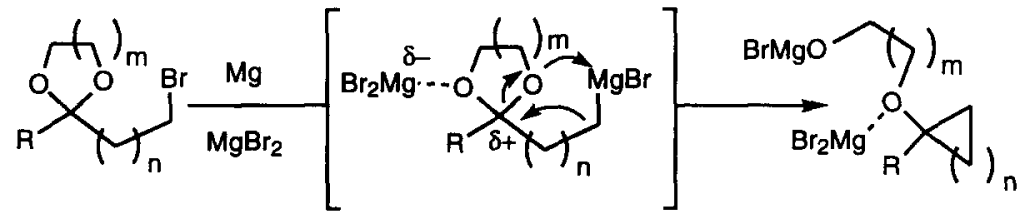

When 1,3-oxothiolane derivative 6 reacts under the same conditions, the C-S bond is cleaved regioselectively to give $6 \mathbf{a}$ as the product. Since $\mathrm{MgBr}_{2}$ is a hard Lewis acid, it is expected to complex preferentially to the hard 
oxo atom and therefore the C-S bond is cleaved selectively through the cyclic transition state. This result agrees with the previous model proposed for the 1,3-dioxolane system.

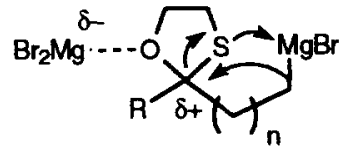

Favored hard acid-hard base interaction

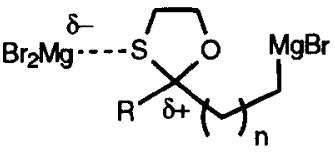

Disfavored hard acid-soft base interaction

For 18, instead of the cyclization product, thioethanol 18a was isolated in high yield. We tentatively attributed this to the formation of sulfonium salt 19 that would be hydrolyzed finally to afford 18a as the major product.

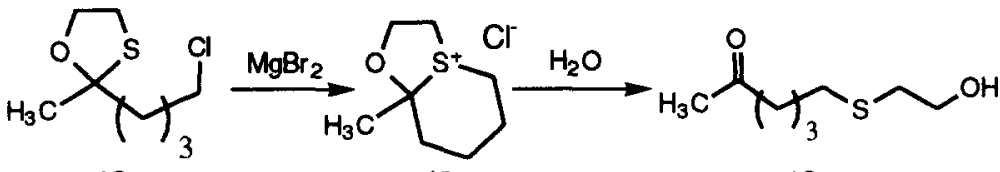

18

19

$18 \mathbf{a}$

In the case of spiro-ketal 9, perhaps due to ring-strain in the transition state, hydride transfer preferentially occurs to give terminal olefin $9 \mathrm{a}$ as the major product. Hydride transfer commonly occurs in the reaction of sterically hindered alkyl magnesium halides with ketones, giving rise to alcohols as the reduction products. ${ }^{7}$

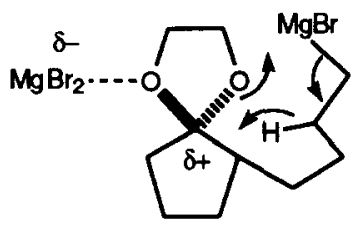

Following the success of previous cyclizations, our attention turned next to the 2-bromoalkenyl derivatives 10-13. Again the five-membered ring precursor 10 cyclized most effectively under our conditions to afford 10a in high yield. In addition, when the less strained six-membered 1,3-dioxane precursor 13 was employed, no cyclization product could be isolated.

Under no condition could the one-step cyclization of $\omega$-haloalkylesters be performed, according to previous literature, ${ }^{7}$ our reaction conditions were successfully applied to $\omega$-haloalkylorthoesters 14-17 to give protected cycloalkanones 14a-17a in moderate yields. This reaction is particularly useful for preparing cyclopropanone derivatives in one step.

In summary, our Lewis-acid catalyzed reaction conditions provide a mild and effective way for the Barbier type one-step cyclization. Application of this reaction to other systems is under investigation.

A general procedure is described as follows: To a suspension of $\mathrm{Mg}$ powder $(1.6 \mathrm{~g}, 65 \mathrm{mmol})$ and iodine (catalytic amounts) in ether $(6 \mathrm{~mL})$ was added slowly $\mathrm{BrCH}_{2} \mathrm{CH}_{2} \mathrm{Br}(9.3 \mathrm{~g}, 44 \mathrm{mmol})$ in ether $(15 \mathrm{~mL})$. The reaction is exothermic and should be cooled in an ice-bath. After complete addition of $\mathrm{BrCH}_{2} \mathrm{CH}_{2} \mathrm{Br}$, a solution of $1(1.78 \mathrm{~g}, 10 \mathrm{mmol})$ in ether $(5 \mathrm{~mL})$ was added dropwise. The reaction mixture was then kept at reflux temperature for $25 \mathrm{~h}$, quenched by addition of aqueous $\mathrm{NH}_{4} \mathrm{Cl}$, extracted with $\mathrm{CH}_{2} \mathrm{Cl}_{2}$, chromatographed on silica gel, using ethyl acetate-hexanes (1:4 to 1:3) as eluent to give a colorless oily product $1 \mathrm{a}(1.25 \mathrm{~g}, 87 \%)$. 


\section{Acknowledgements}

We thank the National Science Council of the Republic of China (NSC-88-2113-M-002-019 and -020) for financial support.

\section{References and Notes}

1. (a) Greene, T. W.; Wuts, P. G. M. Protective Groups in Organic Synthesis, 2 nd. Wiley : New York, 1990. (b) Kocienski, P. J. Protective Groups; Thieme: New York, 1994.

2. (a) Feugeas, C.; Bull. Soc. Chim Fr. 1963, 2568. (b) Blomberg, C.; Hartog, F. A. Synthesis 1977, 18.

3. For examples, see (a) van der Gen, A.; Wiehaupt, K.; Swoboda, J. J.; Dunathan, H. C.; Johnson, W. S. J. Am. Chem. Soc. 1973, 95, 2656. (b) Johnson, W. S.; Wiehaup, K.; Brady, S. F.; Olsen, G. L. J. Am. Chem. Soc. 1974, 96, 3979. (c) Poller, R. C.; Abbas, S. Z. J. Chem. Soc., Dalton Trans. 1974, 1769. (d) Casals, P. F.; Ferard, J. Tetrahedron Lett. 1974, 2483. (e) Forbes, C. P.; Wenteler, G. L.; Wiechers, A. J. Chem. Soc., Perkin Trans. 1 1977, 2353. (f) Sworin, M.; Neumann, W. L. Tetrahedron Lett. 1987, 3217.

4. For a review, see: Bickelhaupt, F. Angew. Chem., Int. Ed. Engl. 1987, 26, 990.

5. For references of Lewis-acid assisted mechanisms, see (a) Mukaiyama, T.; Murakami M. Synthesis 1987, 1043. (b) Ishihara K.; Mori, A.; Yamamoto, H. Tetrahedron 1990, 46, 4595. (c) Denmark, S. E.; Almstead, N. G. J. Org. Chem. 1991, 56, 6458; J. Am. Chem. Soc. 1991, 113, 8089. (d) Ishihara K.; Hanaki. N: Yamamoto, H. J. Am. Chem. Soc. 1993, 115, 10695. (e) Alexakis, A.; Mangeney, P. Tetrahedron: Asymmetry 1990, 1, 477. (f) Hunter, R.; Bartels, B. J. Org. Chem. 1993, 58, 6756. (g) Fujioka, H.; Kitagawa, H.; Matsunaga, N.; Nagatomi, Y.; Kita, Y. Tetrahedron Lett. 1996, 2245. (h) Sammakia, T.; Smith, R. J. Am. Chem. Soc. 1992, 114, 10998; J. Org. Chem. 1992, 57, 2997. (i) Mori, A.; Fujiwara, J.; Maruoka, K.; Yamamoto, H. J. Organomet. Chem. 1985, 285, 83. (j) Mori, I.; Ishihara, K.; Flippin, L. A.; Nozaki, K.; Yamamoto, H.; Barlett, P.; Heathcock, C. H. J. Org. Chem. 1990, 55, 6107. (k) Mallory, R.; Rovinski, S.; Kohen, F.; Scheer, I. J. Org. Chem. 1967, 32, 1417. (1) Ishikawa, H.; Mukaiyama, T.; Ikeda, S. Bull. Chem. Soc. Jpn. 1981, 54, 776. (m) Westera, G.; Blomberg, C.; Bickelhaupt, F. J. Organomet. Chem. 1978, 144, 285. (n) Westera, G.; Blomberg, C.; Bickelhaupt, F. J. Organomet. Chem. 1978, 144, 285, 290. (o) Yuan, T. M.; Yeh, S. M.; Hsieh, Y. T.; Yuan, T. M. J. Org. Chem. 1994, 59, 8192.

6. Mendolini, L. Adv. Phys. Org. Chem. 1986, $22,1$.

7. Cowan, D. O.; Mosher, H. S. J. Org. Chem. 1962, 27, 1. 